\title{
Beta Thalassemia Plus Structural Variants
}

National Cancer Institute

\section{Source}

National Cancer Institute. Beta Thalassemia Plus Structural Variants. NCI Thesaurus. Code C95538.

A heterozygous state in which a person has a mutation in a beta globin allele causing beta thalassemia, together with other structural variants in the other allele. 